\title{
Synthesis and Characterization of Fibre Reinforced Silica Aerogel Blankets for Thermal Protection
}

\author{
S. Chakraborty, ${ }^{1}$ A. A. Pisal, ${ }^{2}$ V. K. Kothari, ${ }^{1}$ and A. Venkateswara Rao $^{2}$ \\ ${ }^{1}$ Department of Textile Technology, IIT, New Delhi 110016, India \\ ${ }^{2}$ Air Glass Laboratory, Department of Physics, Shivaji University, Kolhapur, Maharashtra 416 004, India \\ Correspondence should be addressed to A. Venkateswara Rao; avrao2012@gmail.com
}

Received 24 November 2015; Revised 10 February 2016; Accepted 17 February 2016

Academic Editor: Antonio Riveiro

Copyright (c) 2016 S. Chakraborty et al. This is an open access article distributed under the Creative Commons Attribution License, which permits unrestricted use, distribution, and reproduction in any medium, provided the original work is properly cited.

\begin{abstract}
Using tetraethoxysilane (TEOS) as the source of silica, fibre reinforced silica aerogels were synthesized via fast ambient pressure drying using methanol $(\mathrm{MeOH})$, trimethylchlorosilane (TMCS), ammonium fluoride $\left(\mathrm{NH}_{4} \mathrm{~F}\right)$, and hexane. The molar ratio of TEOS/MeOH/(COOH $)_{2} / \mathrm{NH}_{4} \mathrm{~F}$ was kept constant at $1: 38: 3.73 \times 10^{-5}: 0.023$ and the gel was allowed to form inside the highly porous meta-aramid fibrous batting. The wet gel surface was chemically modified (silylation process) using various concentrations of TMCS in hexane in the range of 1 to $20 \%$ by volume. The fibre reinforced silica aerogel blanket was obtained subsequently through atmospheric pressure drying. The aerogel blanket samples were characterized by density, thermal conductivity, hydrophobicity (contact angle), and Scanning Electron Microscopy. The radiant heat resistance of the aerogel blankets was examined and compared with nonaerogel blankets. It has been observed that, compared to the ordinary nonaerogel blankets, the aerogel blankets showed a $58 \%$ increase in the estimated burn injury time and thus ensure a much better protection from heat and fire hazards. The effect of varying the concentration of TMCS on the estimated protection time has been examined. The improved thermal stability and the superior thermal insulation of the flexible aerogel blankets lead to applications being used for occupations that involve exposure to hazards of thermal radiation.
\end{abstract}

\section{Introduction}

Aerogels are cellular solids that feature very low density, high specific surface area and consist of a coherent open porous network of loosely packed, bonded particles or fibres whose voids are filled with gas. They comprise particle and pore dimensions in the range of 1 to $1000 \mathrm{~nm}$. Aerogels have a wide range of exceptional properties such as lowest thermal conductivity $(\sim 0.01 \mathrm{~W} / \mathrm{m} \cdot \mathrm{K})$ that a solid can ever have, high porosity ( $\sim 95$ to $98 \%$ ), high optical transmission (around 90\%) in the visible region, high specific surface area $\left(\sim 1000 \mathrm{~m}^{2} / \mathrm{g}\right)$, low sound velocity $(100 \mathrm{~m} / \mathrm{s})$, low dielectric constant ( 2 to 4$)$, and low refractive index (1.01 to 1.1) $[1,2]$. Due to very low thermal conductivity, low density, high porosity, and small pore sizes (1 to $1000 \mathrm{~nm}$ ) aerogels are regarded as one of the best insulating materials [3-7]. However, from the point of view of applications, aerogels have the drawback that they absorb moisture from the atmosphere, they are fragile, they cannot be easily handled, and they cannot be used to insulate complex shaped bodies [8]. Therefore, fibre reinforced aerogel fabric has been produced as an alternative to achieve better flexible, drapable, and durable insulation materials. Fibrous materials that may be used as the reinforcing material can be a nonwoven fabric $[9,10]$.

Fibre reinforced aerogel blankets find applications in the construction of heat and flame resistant protective clothing for industrial workers, for protection against thermal hazards of an electrical arc, protective clothing for workers exposed to molten substances and related hazards, and firefighter protective clothing. Such protective gear requires light weight clothing which offers high thermal protection and comfort. Protective clothing, such as that used by a structural firefighter, is usually a multilayered one, with an outer layer, thermal insulation layer, and an inner layer. In which form and how the aerogel can be utilized to effectively enhance 
TABLE 1: Details of the fabrics used for making three layered assembly for evaluation.

\begin{tabular}{lcccc}
\hline Fabric & Cover $(\%)$ & GSM $\left(\mathrm{g} / \mathrm{m}^{2}\right)$ & Thickness $(\mathrm{mm})$ & Bulk density $\left(\mathrm{kg} / \mathrm{m}^{3}\right)$ \\
\hline Nomex IIIA fabric & 0.94 & 220 & 0.44 & 500 \\
Nomex nonwoven felt & - & $\sim 150$ & 2.85 & 52 \\
Modacrylic/cotton fabric & 0.86 & 196 & 0.41 & 478 \\
\hline
\end{tabular}

protective performance of such a clothing assembly are yet to be explored properly. Aerogel nanoparticle coated fabrics for firefighting applications were found to have increased thermal resistance, good air permeability, and moisture management properties [11]. Results of the superior thermal protection of lightweight firefighter protective clothing using aerogel fillers have been reported $[12,13]$. Fire penetration and burn testing of fire blanket materials showed aerogel blankets to be a top performing insulation material [14].

Nonwoven felt produced from inherently heat retardant fibrous materials is used as component of protective clothing for protection against high heat exposure. In the present study, meta-aramid fibre, namely, Nomex, has been used for making nonwoven felt. We have produced low density hydrophobic flexible tetraethoxysilane (TEOS) based silica aerogel blankets via sol-gel formation inside metaaramid (Nomex) needle punched fabric, silylation with trimethylchlorosilane (TMCS), and ambient pressure drying. Subsequently, the prepared aerogel-fabric samples were characterized by density, thermal conductivity, hydrophobicity, organic and inorganic bond formation, and protective evaluation to radiant heat fluxes.

\section{Experimental Procedures}

2.1. Materials. The chemicals used for the preparation of silica alcosols and the subsequent silylation of silica alcogel blankets were tetraethoxysilane (TEOS, 98\%, (Sigma Aldrich)), oxalic acid $\left((\mathrm{COOH})_{2}, 2 \mathrm{H}_{2} \mathrm{O}\right.$ (Qualigenic Fine Chemicals, India)), ammonium fluoride $\left(\mathrm{NH}_{4} \mathrm{~F}\right.$, (Loba Chemie)), methanol (MeOH, (Merck, India)), and trimethylchlorosilane (TMCS, (Fluka, Puriss grade, Switzerland)) and hexane (Merck, India). Double distilled water was used for the preparation of all the solutions. Nomex (DuPont, India) $\mathrm{m}$-aramid fibre matrix was used for making the nonwoven felt which was subsequently used to produce aerogel blanket. Commercially available Nomex IIIA (Nomex 93\%, Kevlar 5\%, and $2 \%$ antistatic fibre) woven fabric and modacrylic cotton $(60 / 40)$ blended woven fabric were used in combination with aerogel blanket for thermal protective evaluation. Threelayer assembly was prepared using a Nomex IIIA woven fabric as outer layer, aerogel blanket as middle layer, and a modacrylic/cotton fabric (blend 60/40) as the inner layer for evaluation of the radiant heat protection. Particulars of the fabrics used for the present study are given in Table 1.

2.2. Methods of Preparation. Nomex (DuPont m-aramid) fibres of 2.2 Denier (denier defined as gram $/ 9 \mathrm{~km}$ ) and $50 \mathrm{~mm}$ length were converted into fibrous nonwoven batting on a laboratory model needle punching machine (Dilo, Germany). The needle punched fabric was prepared with 150 punches $/ \mathrm{m}^{2}, 10 \mathrm{~mm}$ needle penetration depth and set to have areal density of approximately $150\left(\mathrm{~g} / \mathrm{m}^{2}\right)$. Silica aerogel blanket was prepared by forming silica based gel on the Nomex fibrous nonwoven fabric and subsequently transformed into aerogel by suitable drying technique. The aerogel was produced through a two-step acid-base sol-gel process followed by ambient pressure drying. Figure 1 shows a flowchart for the preparation of aerogel-nonwoven batting. The sol was prepared using TEOS precursor diluted in $\mathrm{MeOH}$. The acidic catalyst, oxalic acid $\left((\mathrm{COOH})_{2}, 0.001 \mathrm{M}\right)$, was added to the sol, stirred for 1 hour, and kept at room temperature for 12 hours for hydrolysis. The molar ratio of TEOS : $\mathrm{MeOH}:(\mathrm{COOH})_{2}: \mathrm{NH}_{4} \mathrm{~F}$ was kept constant at $1: 38: 3.73 \times 10^{-5}: 0.023$, respectively. After 12 hours of hydrolysis, the base catalyst, ammonium fluoride $\left(\mathrm{NH}_{4} \mathrm{~F}\right.$, $0.5 \mathrm{M})$, was added dropwise to the sol while stirring and stirred for further $5 \mathrm{~min}$. Immediately after that, the sol was poured onto the Nomex fibrous batting $(6.5 \mathrm{~cm} \times 6.5 \mathrm{~cm}$; density, $52 \mathrm{~kg} / \mathrm{m}^{3}$; thickness, $3.85 \mathrm{~mm}$ ) kept on Petri dish and allowed to form gel at room temperature. The complete gel formation took place within $5 \mathrm{~min}$. Petri dishes containing the alcogel samples in methanol were kept wrapped with aluminum foil and aged for 1 hour. After aging, methanol was decanted and the samples were transferred from Petri dishes to a separate container and surplus of hexane was added. Methanol in the gel was exchanged with hexane at $50^{\circ} \mathrm{C}$ in a shaker (Remi Instrument, India) at $120 \mathrm{rpm}$, for 3 hours. To make the gels hydrophobic and to have the spring-back effect, subsequently the gels were immersed in a silylating agent (TMCS in hexane) and kept in an oven for 16 hours at $50^{\circ} \mathrm{C}$ and shaken at $120 \mathrm{rpm}$. The concentration of TMCS was varied from 2 to $10 \%$ in the solvent (hexane). The unreacted TMCS was exchanged with the hexane solvent again in the same shaker at $50^{\circ} \mathrm{C}$ for 4 hours at $120 \mathrm{rpm}$. After this step, the hexane was decanted and the resulting silylated gelled fabric was dried in an oven at $50^{\circ} \mathrm{C}$ for 1 hour and $100^{\circ} \mathrm{C}$ for 2 hours to get the hydrophobic aerogel composite fabric.

2.3. Reaction Mechanism. In the present study, the surface chemical modification of the wet gelled fabric was made with TMCS in hexane. It took place according to the mechanism shown in Scheme 1.

In order to obtain low density and better hydrophobic silica aerogel fabric, the H's of the surface hydroxyl groups formed during hydrolysis and condensation must be replaced with the organosilicon groups $\left[\left(\mathrm{CH}_{3}\right)_{3}-\mathrm{Si}-\right]$. Therefore, the surface modification of TEOS based wet gel blankets was 

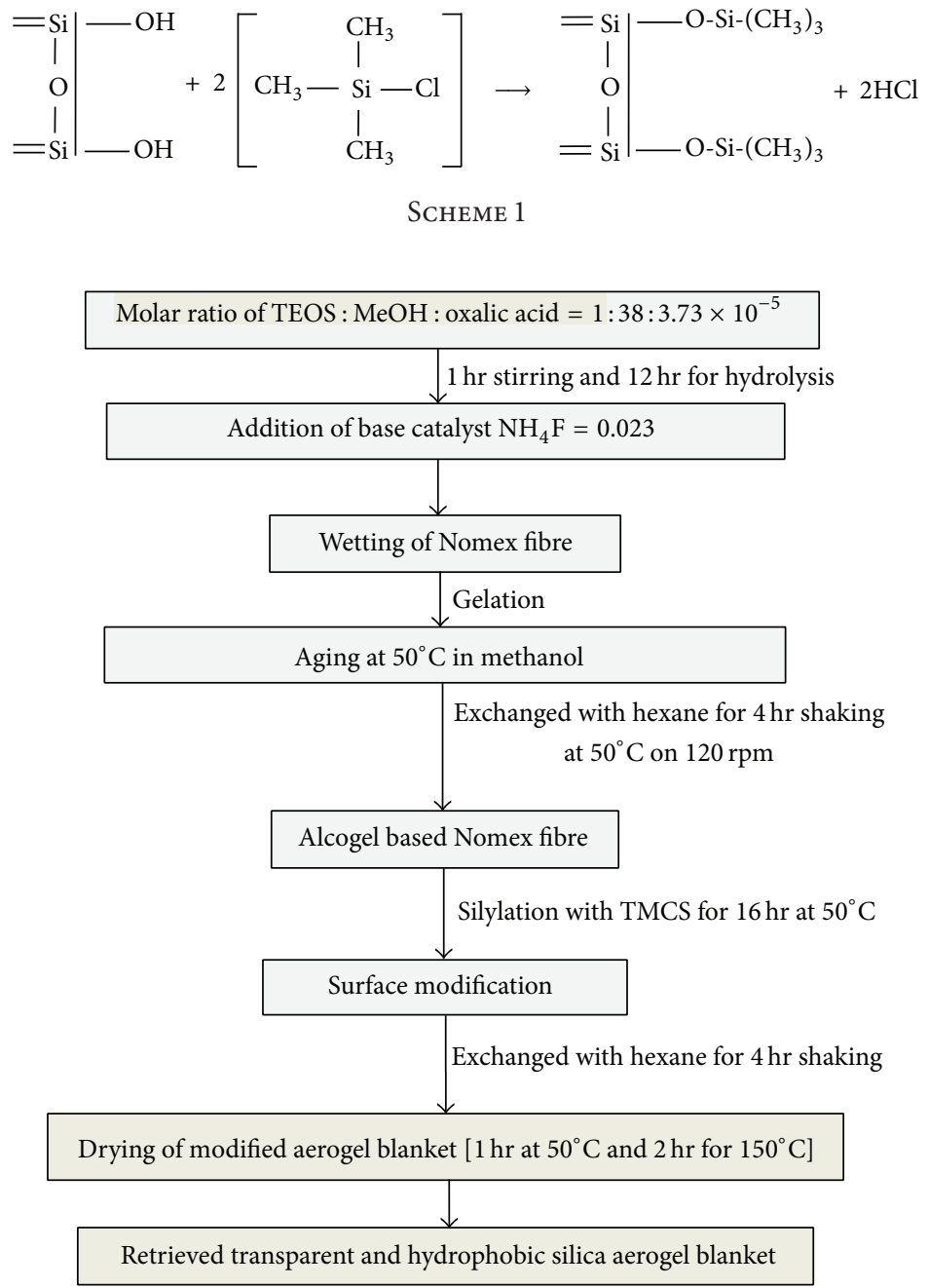

FIGURE 1: Flow chart of the experimental procedure for the preparation of the aerogel blanket.

carried out with TMCS in hexane. The governing chemical reactions are shown as follows:
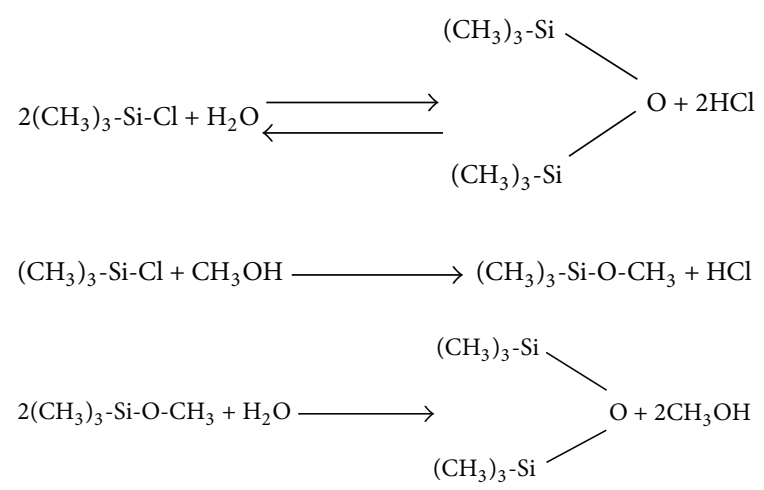

$\left(\mathrm{CH}_{3}\right)_{3}-\mathrm{Si}-\mathrm{O}-\mathrm{CH}_{3}+\mathrm{HCl} \longrightarrow\left(\mathrm{CH}_{3}\right)_{3}-\mathrm{Si}-\mathrm{Cl}+\mathrm{CH}_{3} \mathrm{OH}$

$\left(\mathrm{CH}_{3}\right)_{3}-\mathrm{Si}-\mathrm{Cl}+\equiv \mathrm{Si}-\mathrm{OH} \longrightarrow \equiv \mathrm{Si}-\mathrm{O}-\mathrm{Si}\left(\mathrm{CH}_{3}\right)_{3}+\mathrm{HCl}$

$\left(\mathrm{CH}_{3}\right)_{3}-\mathrm{Si}-\mathrm{O}-\mathrm{CH}_{3}+\equiv \mathrm{Si}-\mathrm{OH}$ $\equiv \mathrm{Si}-\mathrm{O}-\mathrm{Si}\left(\mathrm{CH}_{3}\right)_{3}+\mathrm{CH}_{3} \mathrm{OH}$
As shown in reaction (1), the reaction between trimethylchlorosilane (TMCS) and pore water yields hexamethyldisiloxane (HMDSO) and $\mathrm{HCl}$, and as it happens very rapidly, it may cause cracking of the gel. In order to avoid the reaction between TMCS and pore water directly, prior to the surface modification, the pore water of silica hydrogel was exchanged with hexane. The hexane solvent used in the reaction mixture helps to decrease both the reaction rate of TMCS with the pore water and the capillary stress during drying due to its low surface tension.

2.4. Methods of Characterization. The apparent density of the aerogel-fabric composites was obtained from the measurement of weight of the samples (in grams) using a microbalance with an accuracy of up to $10^{-4} \mathrm{~g}$, with the known aerogel-fabric composites volume. The Fourier Transform Infrared (FTIR) spectroscopy studies were carried out using Perkin Elmer (Model number 760) IR spectrophotometer in the range of $400-4000 \mathrm{~cm}^{-1}$. The spectroscopic analysis of the samples was carried out using attenuated total internal reflection technique (ATR). Microstructural studies of 


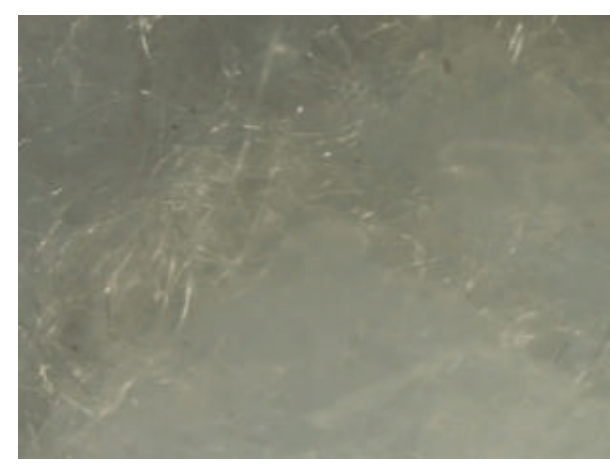

(a)

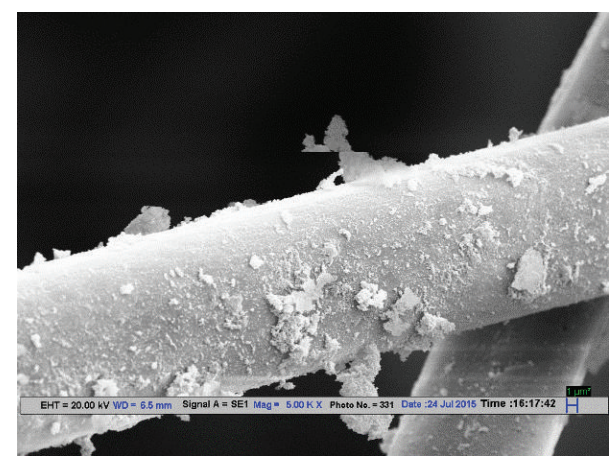

(c)

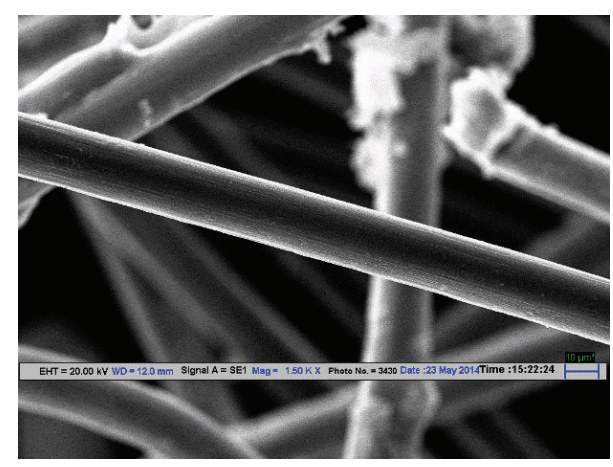

(b)

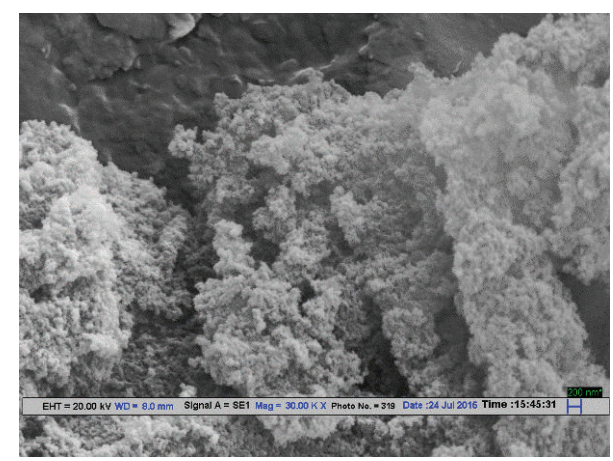

(d)

FIGURE 2: Microscopic view and SEM of an aerogel blanket: (a) ordinary microscopic image (30x), (b) Nomex fibrous batting (1.5Kx), (c) aerogel-fibre blanket $(3.0 \mathrm{Kx})$, and (d) aerogel in between the fibres $(30.0 \mathrm{Kx})$.

the silica aerogel blankets were carried out using scanning electron microscope (SEM). The hydrophobicity of the aerogel blankets was determined using a contact angle meter (Krüss, DSA 100). The thermal conductivity $(\lambda)$ of the silica aerogel blankets was measured using thermal conductivity meter, Alambeta [15], which measures the thermal resistance, thermal conductivity with an accuracy of $0.0001 \mathrm{~W} / \mathrm{m} \cdot \mathrm{K}$. The radiant heat resistance of the aerogel blanket was evaluated on an instrument developed based on the principle outlined in ASTM F 1939 (Standard Test Method for Radiant Heat Resistance of Flame Resistant Clothing Materials with Continuous Heating), where the aerogel blankets were exposed to a radiant heat flux of very high intensity and the temperature was measured at the other side of the fabric using a copper calorimeter of known mass and thickness. Cumulative heat $\left(\mathrm{J} / \mathrm{cm}^{2}\right)$ was plotted with time and the time taken to cross Stoll 2nd degree burn injury; the curve [16] has been used as a standard reference to compare the thermal insulation and heat resistant properties of the aerogel blankets.

\section{Results and Discussion}

3.1. Scanning Electron Microscopy. The silica aerogel fibrous composite blankets were examined under ordinary Nikon microscope at 30x magnification, Figure 2(a), and it has been observed that a semitransparent aerogel formed in the fibrous matrix. The SEM structure of a single unmodified Nomex fibre (1.5x) is shown in Figure 2(b) and it can be compared to a fibre after aerogel was formed as shown in Figure 2(c). The SEM image of the aerogel-fibre blanket at $3 \mathrm{~K}$ magnification shows granular appearance of the aerogel deposited on the fibre, indicating the change in the nature of the surface of the fibres. The SEM image of the aerogel at 30,000x is shown in Figure 2(d). The SEM images shown in Figures 2(c) and 2(d) show a three-dimensional interconnected aerogel and its macroporous structures. Thus, the fine macroporous structures of the aerogel blanket have been observed. With smaller size of the particles, more discontinuities are created and resulted in increased thermal contact resistance and discontinuous solid backbones, which impedes heat transfer.

3.2. Density and Thermal Conductivity Measurements. The density of the silica aerogel blankets was determined by taking weight of the samples on an electronic microbalance of an accuracy up to $10^{-4} \mathrm{~g}$ and from volume of the sample based on its length, width, and thickness. The thermal conductivity determines both the steady state and transient state thermal properties of thin insulation materials like a textile fabric. The thermal conductivity $(\mathrm{W} / \mathrm{m} \cdot \mathrm{K})$ was determined at the end of the transient phase. The measured bulk density and thermal conductivity of the aerogel blankets with the variation of the molar ratio of silylating agent TMCS/TEOS are shown the Figure 3. It has been observed that the bulk density of the parent Nomex blanket increases as they are made from the aerogel blankets, but it gradually decreases with an increase of the TMCS/TEOS molar ratio. The initial increase 


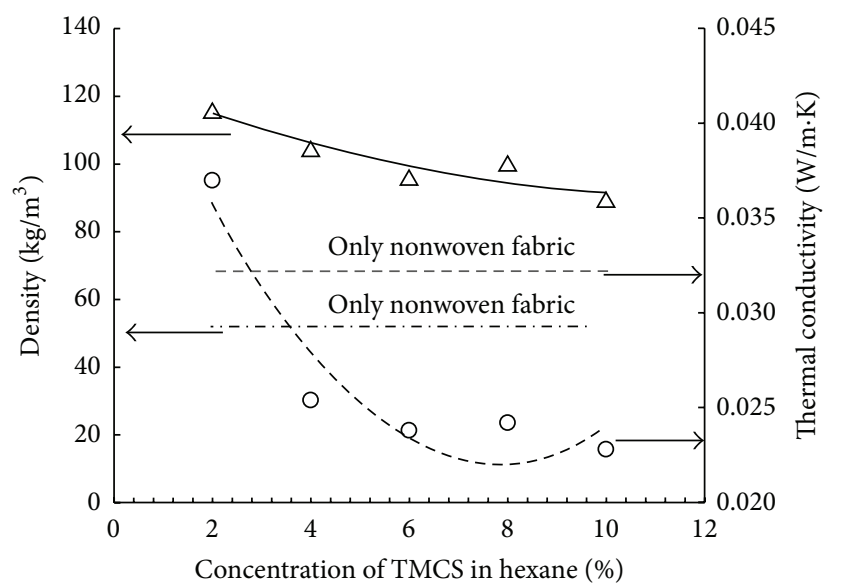

$\triangle$ Density $\left(\mathrm{kg} / \mathrm{m}^{3}\right)$

O Thermal conductivity $(\mathrm{W} / \mathrm{m} \cdot \mathrm{K})$

FIGURE 3: Density and thermal conductivity of the aerogel blankets.

in the density is due to the formation of solid hydrophobic aerogels inside the pores and around the fibres of the fibrous materials. Higher density at lower TMCS concentration can be attributed to the fact that lower TMCS concentration leads to cluster surfaces formed with a few $\mathrm{Si}-\left(\mathrm{CH}_{3}\right)_{3}$ formed, unmodified surface silanols, and the formation of dense silica aerogels due to the condensation of silanol groups. The increase in volume percentage of TMCS (in hexane) increases the hydrophobization; more number of trimethylsilyl groups get attached to the silica surface minimizing the condensation reaction leading to an increase in pore volume and hence a decrease in the density of the aerogels. The aerogels with higher pore volume are obtained as more hydrophobization prevents the condensation of the silanol groups and hence prevents the structural collapse of the silica gel network, which occurs due to capillary forces, developed during the drying process. The aerogel consists of macropores having characteristic diameter of 1-1000 nm, depending upon the density of the composite aerogels [17]. The mean free path of gas molecules in air at a pressure of $1 \mathrm{bar}$ is $70 \mathrm{~nm}$, which is comparable to the average aerogel pore size [18]. Hence, though there is a weight gain and increase in bulk density for all the aerogel-fabric samples, the overall thermal conductivity decreased, as the aerogel material partially suppresses the gas phase conduction and also the aerogel matrix formed in between the fibrous contact points decreases solid phase conductivity. The initial increase in thermal conductivity can be due to increase in bulk density, and the further decrease can be due to decrease in bulk density and decrease in the solid phase conduction. In the case of the aerogelfibre composite blankets, fibres reduce the thermal radiation transport and at the same time enhances the strength and flexibility of the aerogel blankets [17].

3.3. Fourier Transform Infrared Spectroscopy. Figure 4 shows the FTIR spectra of silica aerogel blankets with varying amounts of the silylating agent. It is clearly seen from

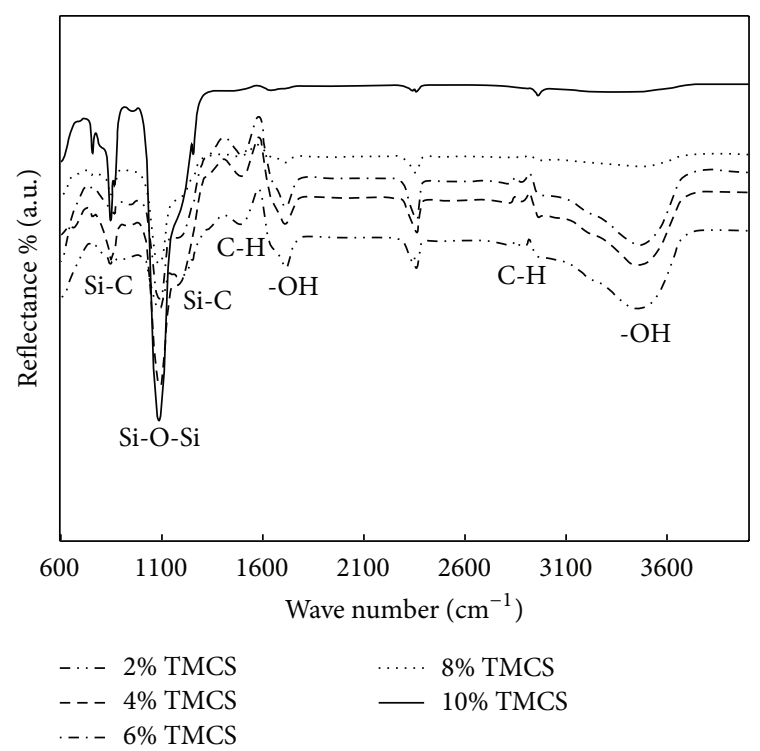

FIGURE 4: FTIR spectra of the aerogel blanket.

the figure that the peak at around $1600 \mathrm{~cm}^{-1}$ belongs to adsorbed $\mathrm{H}_{2} \mathrm{O}$ and the broad peak at around $3500 \mathrm{~cm}^{-1}$ is due to $\mathrm{Si}-\mathrm{OH}$ groups. With increasing the TMCS concentration it can be noticed that the intensity of the absorption peaks related to $\mathrm{Si}-\mathrm{OH}$ decreases confirming the increased hydrophobicity of the aerogel blankets. This has been further correlated with the finding of the contact angle studies (the more the TMCS, the more the contact angle). The peaks occurring at around $1250,860 \mathrm{~cm}^{-1}$ are due to $\mathrm{Si}-\mathrm{CH}_{3}$ bonds, and the peaks around 2980 and $1450 \mathrm{~cm}^{-1}$, respectively, are related to $\mathrm{C}-\mathrm{H}$ bonds. Absorption peaks due to bending and stretching of C-H bonds at $1450 \mathrm{~cm}^{-1}$ and $2980 \mathrm{~cm}^{-1}$ appear to be prominent. The intensity of the peaks at around 860 and $1250 \mathrm{~cm}^{-1}$ due to Si-C bonds becomes sharp with increased TMCS concentration, confirming the hydrophobic modification of the aerogel blanket surfaces [19-21].

3.4. Contact Angle Measurements. A contact angle measuring instrument (Krüss, DSA 100) has been used to measure the contact angle of different aerogel blanket samples. A $10 \mu \mathrm{L}$ water droplet was used to measure the contact angle. The image captured by the high resolution camera was collected for all the samples for comparison. The contact angles were measured directly by enlarging the images obtained by the instrument (Figure 5). All the aerogel blanket samples showed excellent hydrophobicity and the sample with the highest proportion of TMCS used showed the contact angle as high as $\sim 165^{\circ}$.

3.5. Thermogravimetric Analysis. The thermogravimetric (TGA) analysis has been carried out to investigate the thermal stability of the silica aerogel blankets in air atmosphere (Figure 6). The initial weight loss around $100^{\circ} \mathrm{C}$ is due to the evaporation of moisture absorbed by the aerogel blankets, which is approximately $4 \%$. In the TGA curve for pure 


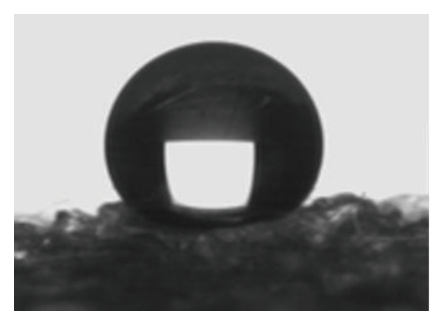

4\% TMCS

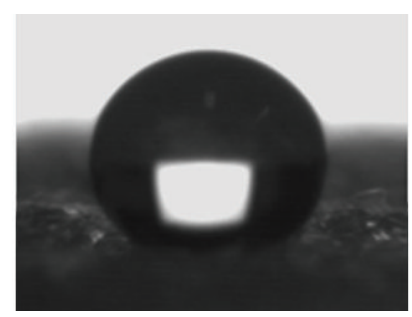

6\% TMCS

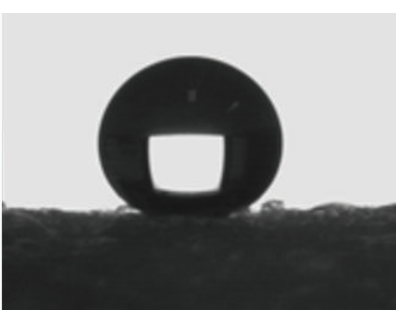

8\% TMCS

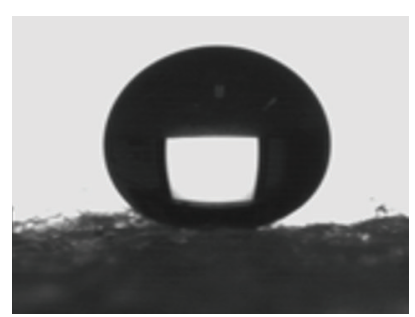

10\% TMCS

FIgURE 5: Photographs showing a water droplet on the surface of silica aerogel blankets obtained at different concentrations of TMCS.

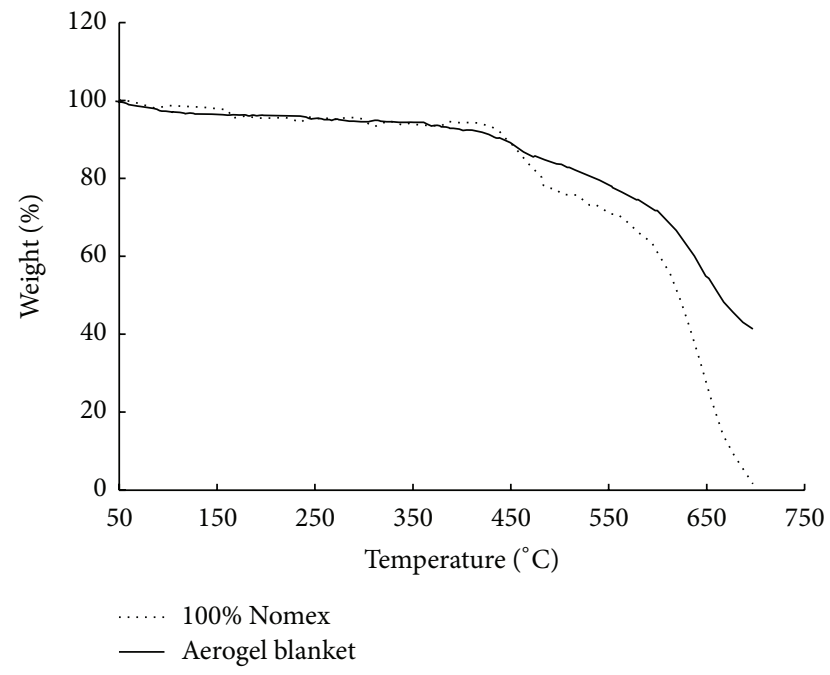

FIGURE 6: Thermogravimetric analysis of $100 \%$ Nomex-III and aerogel-fibre blanket (6\% TMCS).

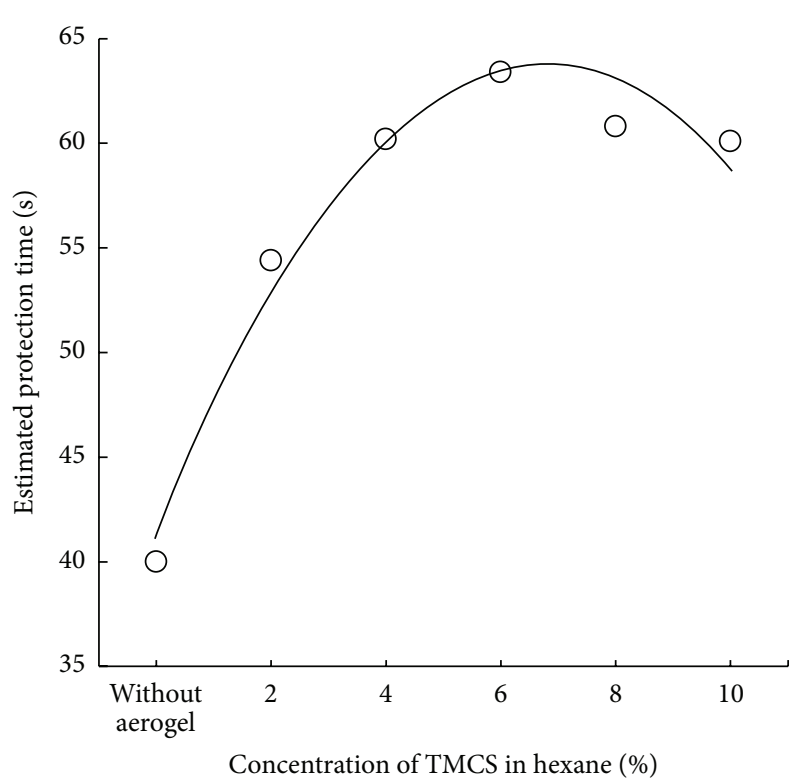

FIGURE 7: Estimated protection time of the aerogel blankets versus the concentration of the TMCS in hexane.

modacrylic/cotton $(60: 40)$ fabric were prepared and tested against the radiant heat. A combination of fabrics which contains a Nomex nonwoven blanket (without aerogel) in the middle layer has been used as a control sample for comparison. All fabric combinations were exposed to a heat flux of $35 \mathrm{~kW} / \mathrm{m}^{2}$ and time (seconds) required to cross the Stoll's curve for burn injury is noted. After each experiment the face of the copper calorimeter used was cleaned to remove the oil and deposits due to charring. The heat flux calibration was repeated from time to time and adjusted. The estimated protection time for all the fabrics is graphically shown in Figure 7. With the use of aerogel blanket in the middle layer, the protective value of the fabric combinations increased significantly. An increase in protection time of $36 \%$ has been observed comparing the first aerogel blanket combination (2\% TMCS) with the control fabric. A maximum protection time of 63.4 seconds ( $58.5 \%$ increase) was observed for the third combination (6\% TMCS). As it has been observed that the thermal conductivity in all aerogel blankets decreased continually with increased TMCS/TEOS ratios, it can be

one of the factors responsible for the increased thermal
3.6. Protective Evaluation of the Aerogel Blankets. The three layered combinations with the $100 \%$ Nomex IIIA (DuPont) woven fabric as the outer layer, the aerogel blankets with different levels of silylation (TMCS concentration in hexane) used in the middle layer, and an inner layer of the 
insulation of the aerogel blankets. The decreasing density of the aerogel blankets can be another reason of increased thermal protection. It appears from the experimental data that a further increase in the concentration of TMCS does not effectively increase insulation. Increased number of Si$\mathrm{CH}_{3}$ groups developed in such samples may not contribute to increase in pore volume and actually supported oxidation at higher temperature and degradation of Nomex fibrous structure of the blankets and did not produce expected reduction in heat transfer.

Considering all the samples, superior insulation and increased thermal protection have been experienced using the aerogel blankets. Fibrous layers absorb most of the infrared radiation and dominant mode of heat transfer is conduction only. In the case of aromatic polyamide fabrics (namely, Nomex outer layer) total transmittance for a heating source at $2000^{\circ} \mathrm{K}$ can be less than $10 \%$ only and no transmission in the infrared region [24]. Heat transfer through these aerogel blankets can be described as for optically thick aerogels. For a given temperature gradient within an aerogel heat is transferred through silica particle network where the mean free path of phonons is far below the dimensions of amorphous, primary dielectric particles. The solid conductivity is also proportional to a density dependent geometrical factor that considers the effect of ineffective dead ends of solid backbone [25]. Characteristic pore size within the aerogels causes gas phase heat transfer to be reduced compared to free air. In conjunction with the reduced solid thermal conductivity and suppressed gas phase heat transfer, aerogel blankets act as excellent thermal insulating materials. In addition, the thermal stability of the aerogel blankets contributes to a great extent to the protection as it has been experimentally observed. At high heat exposure, the Nomex nonwoven felt used as control fabric broke open at the center; though degraded, aerogel blankets did not lose their integrity. However, on exposure to extreme heat $\left(\sim 470^{\circ} \mathrm{C}\right)$, the hydrophobicity of aerogels blankets was lost due to the oxidation of the $-\mathrm{CH}_{3}$ groups as it has been found from the TGA data analysis [23].

\section{Conclusions}

The TEOS based fibre reinforced silica aerogel blankets produced via gelation, silylation, and atmospheric pressure drying route appear to be a very useful thermal insulating material in the case of extreme heat exposure. The hydrophobicity of the aerogel blankets has been found to be increasing with increased silylating agent (trimethylchlorosilane (TMCS)) concentration, which has been confirmed from the FTIR and contact angle measurements. The bulk density and the thermal conductivity of the aerogel blankets were found to reduce with increase in the silylation treatment. Successful trials taken by altering the concentrations of the silylating agent (TMCS) showed great improvement in the estimated protection time from 2 nd degree burn injury. The effectiveness of the silica aerogel blankets as protective shielding has been found to increase, with the increasing TMCS concentration. The aerogel blankets have the applications in the area of firefighting systems.

\section{Competing Interests}

The authors declare that there are no competing interests regarding the publication of this paper.

\section{Authors' Contributions}

S. Chakraborty and A. A. Pisal contributed equally.

\section{Acknowledgments}

The corresponding author (Professor A. Venkateswara Rao) is highly thankful to the University Grant Commission (UGC), New Delhi, India, for funding this work under UGC-BSRFaculty Fellowship Letter no. F. 18-1/2011 (BSR) dated May 21, 2013. One of the authors, Abhijit A. Pisal, is highly grateful to the UGC, New Delhi, for the Stipendiary Candidateship under the UGC-BSR-Faculty Fellowship.

\section{References}

[1] N. Husing and U. Schubert, "Aerogels-airy materials: chemistry, structure, and properties," Angewandte ChemieInternational Edition, vol. 37, no. 1-2, pp. 22-45, 1998.

[2] J. Fricke and T. Tillotson, "Aerogels: production, characterization, and applications," Thin Solid Films, vol. 297, no. 1-2, pp. 212-223, 1997.

[3] E. R. Bardy, J. C. Mollendorf, and D. R. Pendergast, "Thermal conductivity and compressive strain of aerogel insulation blankets under applied hydrostatic pressure," Journal of Heat Transfer, vol. 129, no. 2, pp. 232-235, 2007.

[4] R. Caps and J. Fricke, "Aerogels for thermal insulation," in SolGel Technologies for Glass Producers and Users, pp. 349-353, Springer, New York, NY, USA, 2004.

[5] D. M. Smith, A. Maskara, and U. Boes, "Aerogel-based thermal insulation," Journal of Non-Crystalline Solids, vol. 225, pp. 254259, 1998 .

[6] M. Schmidt and F. Schwertfeger, "Applications for silica aerogel products," Journal of Non-Crystalline Solids, vol. 225, no. 1-3, pp. 364-368, 1998.

[7] H. L. Paul and K. R. Diller, "Comparison of thermal insulation performance of fibrous materials for the advanced space suit," Journal of Biomechanical Engineering, vol. 125, no. 5, pp. 639647, 2003.

[8] A. Katti, N. Shimpi, S. Roy et al., "Chemical, physical, and mechanical characterization of isocyanate cross-Linked aminemodified silica aerogels," Chemistry of Materials, vol. 18, no. 2, pp. 285-296, 2006.

[9] R. Baetens, B. P. Jelle, and A. Gustavsen, "Aerogel insulation for building applications: a state-of-the-art review," Energy and Buildings, vol. 43, no. 4, pp. 761-769, 2011.

[10] Aerogel composite with fibrous batting, US 7078359 B2.

[11] Abu Shaid, M. Furgusson, and L. Wang, “Thermophysiological comfort analysis of aerogel nanoparticle incorporated fabric for fire fighter's protective clothing," Chemical and Materials Engineering, vol. 2, no. 2, pp. 37-43, 2014.

[12] Z. Qi, D. Huang, S. He et al., "Thermal protective performance of aerogel embedded firefighter's protective clothing," Journal of Engineered Fibers and Fabrics, vol. 8, no. 2, pp. 134-139, 2013. 
[13] L. Jin, K. Hong, and K. Yoon, "Effect of aerogel on thermal protective performance of firefighter clothing," Journal of Fiber Bioengineering and Informatics, vol. 6, no. 3, pp. 315-324, 2013.

[14] J. G. R. Hansen and B. J. Frame, "Flame penetration and burn testing of fire blanket materials," Fire and Materials, vol. 32, no. 8, pp. 457-483, 2008.

[15] L. Hes, M. De Araújo, and V. V. Djulay, "Effect of mutual bonding of textile layers on thermal insulation and thermal contact properties of fabric assemblies," Textile Research Journal, vol. 66, no. 4, pp. 245-250, 1996.

[16] A. M. Stoll and M. A. Chianta, "Heat transfer through fabrics as related to thermal injury," Transactions of the New York Academy of Sciences, vol. 33, no. 7, pp. 649-670, 1971.

[17] S.-C. Lee and G. R. Cunnington, "Conduction and radiation heat transfer in high-porosity fiber thermal insulation," Journal of Thermophysics and Heat Transfer, vol. 14, no. 2, pp. 121-136, 2000.

[18] X. Lu, R. Caps, J. Fricke, C. T. Alviso, and R. W. Pekala, "Correlation between structure and thermal conductivity of organic aerogels," Journal of Non-Crystalline Solids, vol. 188, no. 3, pp. 226-234, 1995.

[19] A. P. Rao, A. V. Rao, and G. M. Pajonk, "Hydrophobic and physical properties of the ambient pressure dried silica aerogels with sodium silicate precursor using various surface modification agents," Applied Surface Science, vol. 253, no. 14, pp. 6032-6040, 2007.

[20] A. Venkateswara Rao, S. D. Bhagat, H. Hirashima, and G. M. Pajonk, "Synthesis of flexible silica aerogels using methyltrimethoxysilane (MTMS) precursor," Journal of Colloid and Interface Science, vol. 300, no. 1, pp. 279-285, 2006.

[21] D. Y. Nadargi, S. S. Latthe, H. Hirashima, and A. V. Rao, "Studies on rheological properties of methyltriethoxysilane (MTES) based flexible superhydrophobic silica aerogels," Microporous and Mesoporous Materials, vol. 117, no. 3, pp. 617-626, 2009.

[22] J. R. Brown and B. C. Ennis, “Thermal analysis of Nomex ${ }^{\circledR}$ and Kevlar ${ }^{\circledR}$ fibers," Textile Research Journal, vol. 47, no. 1, pp. 62-66, 1977.

[23] P. M. Shewale, A. V. Rao, J. L. Gurav, and A. P. Rao, "Synthesis and characterization of low density and hydrophobic silica aerogels dried at ambient pressure using sodium silicate precursor," Journal of Porous Materials, vol. 16, no. 1, pp. 101-108, 2009.

[24] J. Quintiere, "Radiative characteristics of fire fighters' coat fabrics," Fire Technology, vol. 10, no. 2, pp. 153-161, 1974.

[25] H.-P. Ebert, “Thermal properties of aerogels," in Aerogels Handbook, Advances in Sol-Gel Derived Materials and Technologies, pp. 537-564, Springer, New York, NY, USA, 2011. 

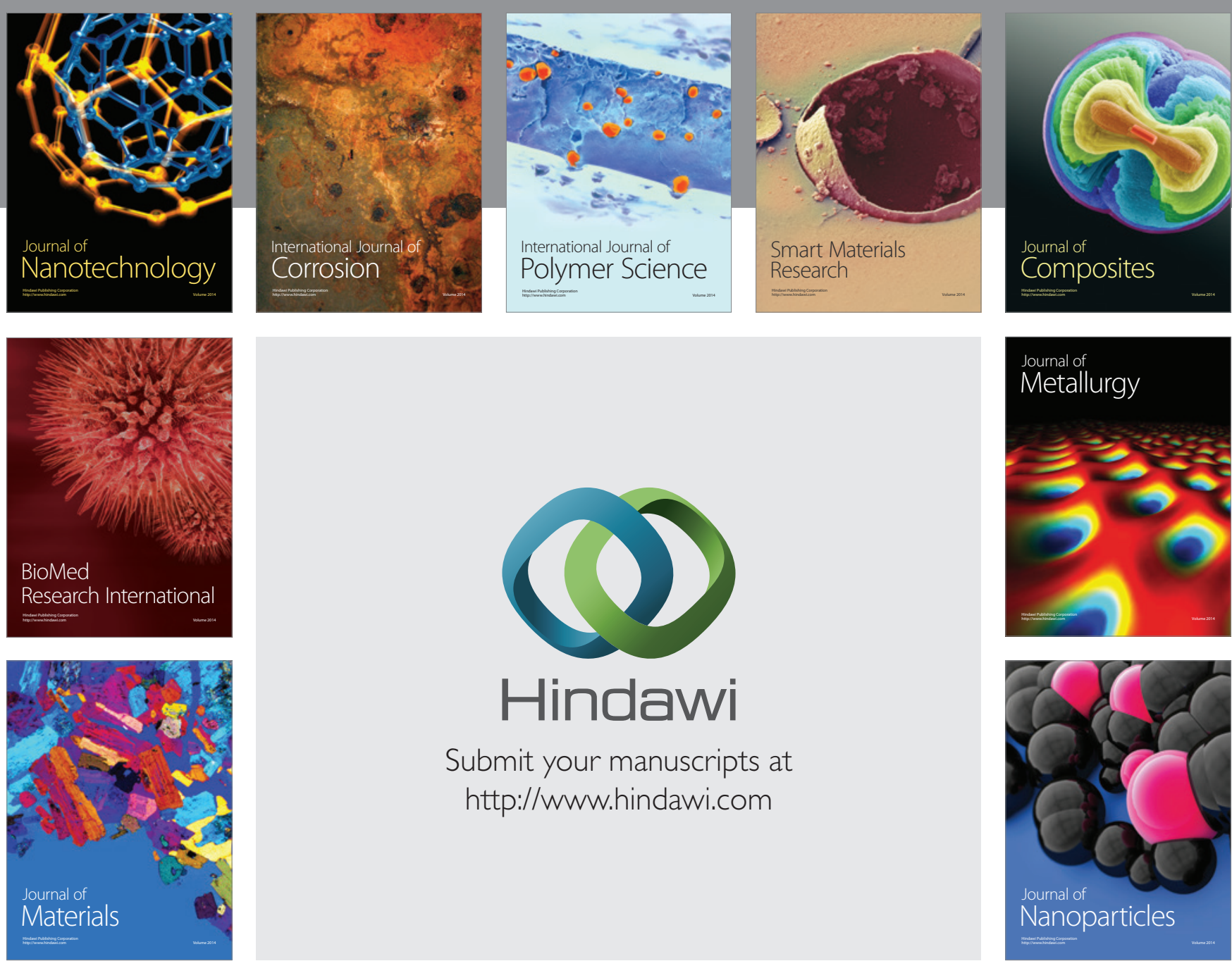

\section{Hindawi}

Submit your manuscripts at

http://www.hindawi.com

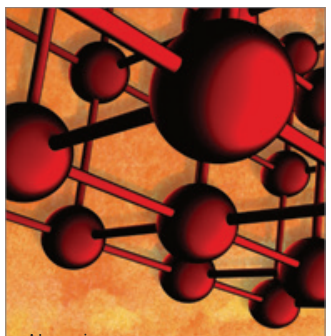

Materials Science and Engineering
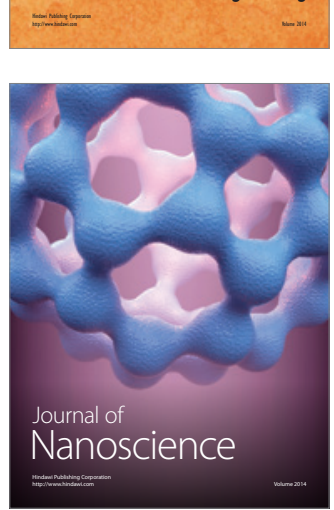
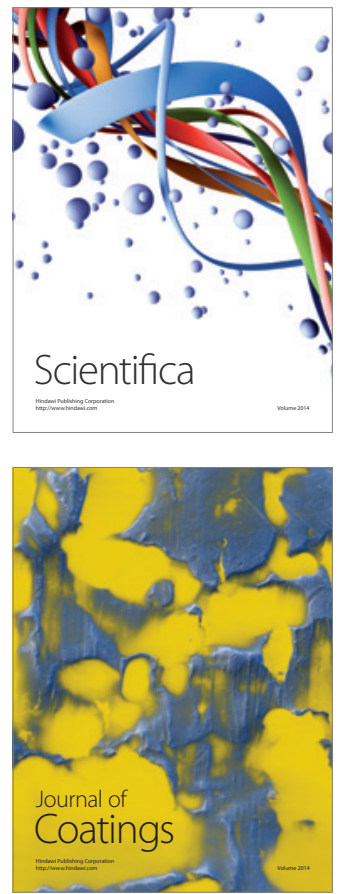
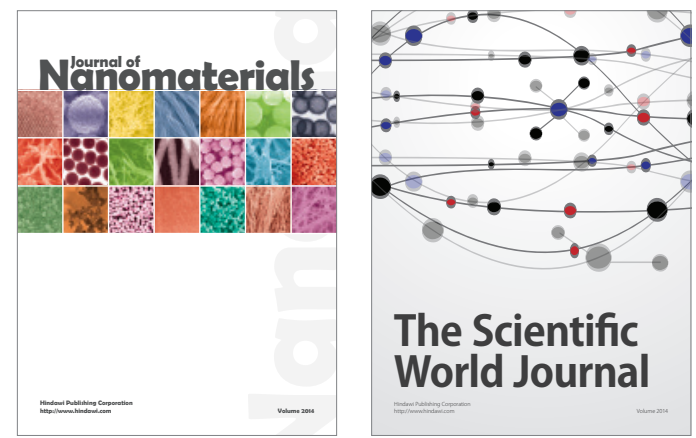

The Scientific World Journal
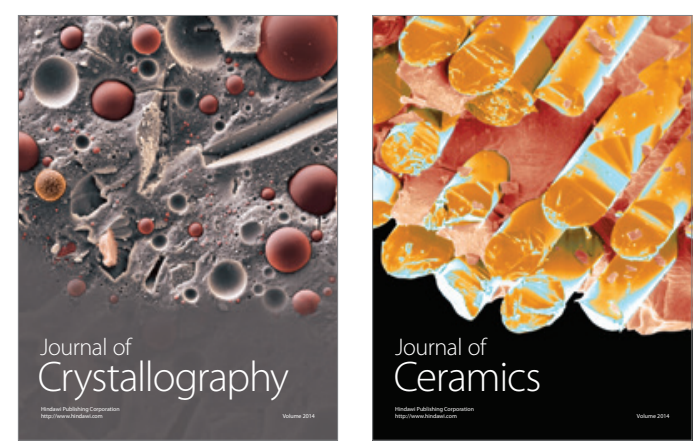
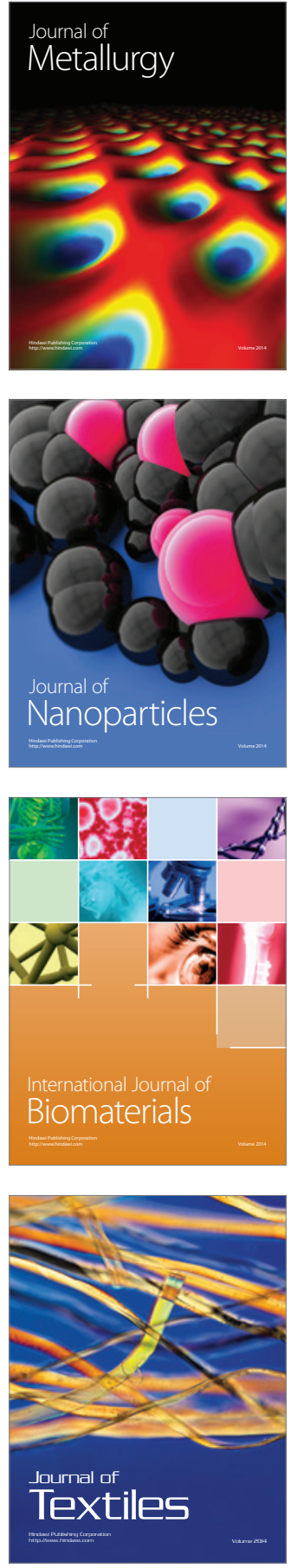